\title{
Design and Implementation of Starting and Extinguishing System for Diesel Motors
}

\author{
Bilal Abdullah Nasir*, Saleh Esaa Jasim, Muneef Abdullah Ahmed \\ Hawijah Technical Institute, Kirkuk, Iraq \\ *Corresponding Author: bilal_alnasir1958@yahoo.co.uk
}

Copyright (C) 2014 Horizon Research Publishing All rights reserved.

\begin{abstract}
In this work a design and implementation of starting and turning - off systems for diesel motors are accomplished. Many of diesel motors, up to date, started by hand, especially those are used in farms irrigation, and those which are used as a turbines connected with AC generators for electricity generation in the houses to substitute the continuous disconnection in electrical supply which developed by the state organization for electricity. The work is implemented by using the car spear part as well as some pieces with different kinds and dimensions, manufactured in the workshop, as a starting system of the diesel motor. The relation between the starting speed with time, for both handle and automatic starting is studied and compared to show the effect of operation-speed on the starting of these types of diesel motors. Also, in this work an electrical circuits and components are designed for a remote stopping of diesel motors as soon as the electrical supply from the state organization for electricity is developed. The automatic starting and stopping of diesel motors facilitate the utilization of these motors for electrical generation without any ability of an accident may be happen during the starting operation of such type of these motors.
\end{abstract}

Keywords Diesel Engines, Automatic Starting, Electric Motors

\section{Introduction}

At the end of the fifties of the last century were car engines run manually [1] reached the bottom front of the car, was indispensable gradually at the beginning of the sixties [2] and replace it with an electric motor small runs using the DC power from the battery and is running the car engine connect the electrical circuit has its own then called the electric motor this engine first movement or initially operating, which is a motor with gear small enamored with the gear large engine and gives so large torque at the beginning and this is necessary to overcome the resistance of the engine and is very convenient to start more than one way recycling manual [3].
It was to take advantage of this electric motor to run the types of engines fueled diesel and relied upon for the purpose of production of electrical energy as well as electric power plants, which are managed by using an electric motor and a diesel engine and turbocharged engine [4], and there are many types of first movement or initially operating engines, including what is electric or diesel engine [5] as well as the first operating chemical or pneumatic [6]. In this research was designed and implemented first movement of a kind electric start and turn off the diesel engines used to generate electric power or for agricultural purposes for being fuel-efficient and low-cost $[7,8]$, and has to take advantage of the electric motor developer to run engines recycling manual used for the production of electric power in Iraq.

In Iraq, where to start production of electric power since 1995, to retreat and not being able to meet the needs of the consumer growing it, so the large proportion of citizens resorted to the production of electrical energy household and production of electrical energy, unfortunately, limited to engines imported high recycling manual cheap price of Origin Indian, and with the need to electric power production and utilization found that a large percentage of the citizens do not possess these engines because they are managed or operated manually as and find rotate the engine initially resisting very large arising from compression and friction so it is difficult for the recycling manual delivery of the engine to the lower rotation speed needed to ignite a mixture of air and fuel inside cylinder engine and generate the torque required for rotation [3].

\section{Design and Installation of Automatic Starter}

Operating starter designed for this type of engine and other, depending on the used car parts [ 9,10 ] and using other iron parts multiple compositions and dimensions, as in figure (1). The first run after installation of all its parts shown in figure (2) .

After several experiments designed models of the first operating diesel engines recycling manual and drum single and multiple cylinders and implemented efficiently so that it 
is installed on these engines easily and take advantage of them, as in figure (3) and thus get rid of the dangers and disadvantages of recycling manual where it went a lot of people victim to ill use the manual lever recycling .Figure (4) shows how to install starter operating on different types of diesel engines .

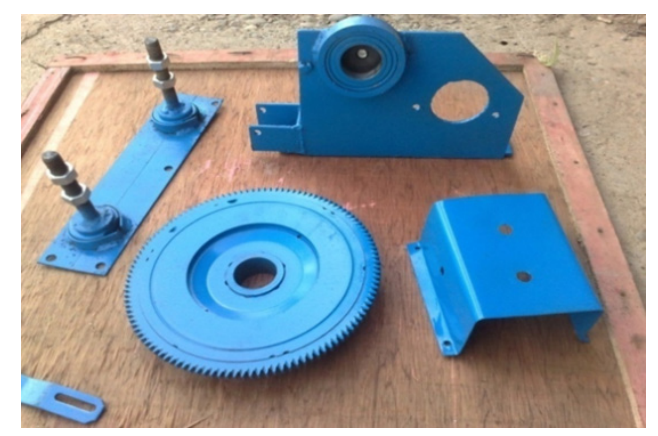

Figure 1. The parts that go into operating starter

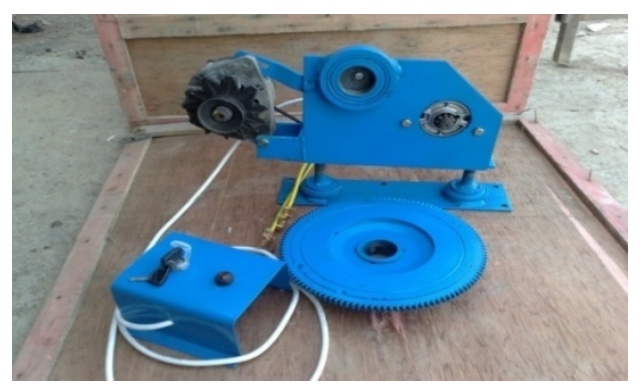

Figure 2. The composite operating starter in all its parts

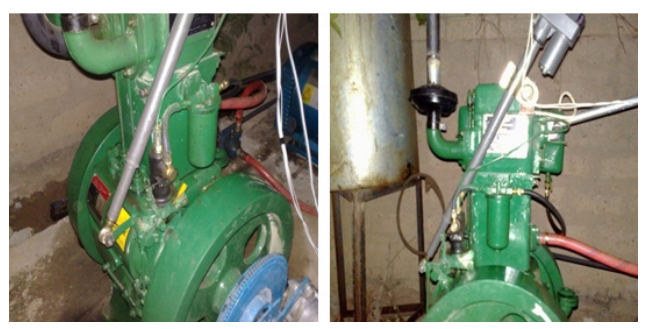

Figure 3. The starter construction on the diesel engine
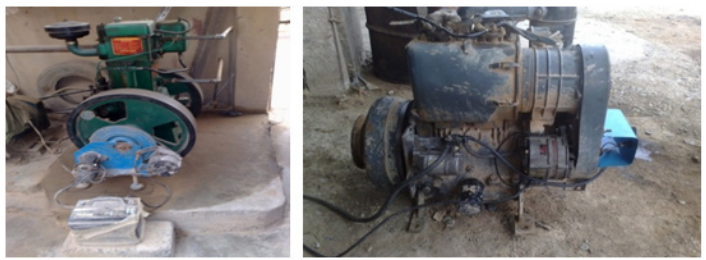

Figure 4. Starter operating on different types of diesel engines

\section{Starting the Diesel Engine}

It should be noted that the operation of motor manually requires effort high and with a speed sufficient to be combustion within the cylinder engine to begin to spin it fails a lot of workers in the operation of such engines do not want to try a second or third because they have been infected with some fatigue or reluctance to use the lever recycling manual because the determined rotational management column engine varies depending on the position of lever recycling manual and as a result of a change in pressure inside the cylinder piston and change the forces of inertia on the piston during manual operation, and as the determined rotational resistant to the direction of rotation of the engine fixed, therefore, increase the speed of rotation manually very necessary for the determination of the rotational constant and overcome the determined resistance of the engine is burning inside the cylinder piston and the engine starts to spin, but if it becomes torque engine manually lower than determined resistor will slow down the engine and fail the operation and the engine starts to spin, so the operation of diesel engines requires payment constant for a fixed rotational torque $(\mathrm{T})$ to the amount of time ( $t)$, even if the rotational speed changed during that period from $\mathrm{W} 1$ to $\mathrm{W} 2$ [11] :

$$
\mathrm{T} * \mathrm{t}=\mathrm{I} *(\mathrm{~W} 2-\mathrm{W} 1)
$$

Where $\mathrm{T}=$ engine torque (Newton meters $)$.

$\mathrm{I}=$ moment of inertia about the axis of rotation of the engine (Kg.m2)

And can calculate engine torque and the moment of inertia from the equations below:

$$
\begin{aligned}
& \mathrm{T}=\mathrm{F} * \mathrm{r} \\
& \mathrm{I}=\mathrm{M} * \mathrm{r} 2
\end{aligned}
$$

Where $\mathrm{F}=$ tangential force ( Newton)

$\mathrm{r}=$ radius of the axis of rotation $(\mathrm{m})$

$\mathrm{M}=\operatorname{mass}(\mathrm{Kg})$

The equation ( 1 ) can be obtained on the angular acceleration of motor rotation is as follows :

$$
\alpha=\mathrm{T} / \mathrm{I}=(\mathrm{W} 2-\mathrm{W} 1) / \mathrm{t}
$$

Where $\alpha=$ angular acceleration ( $\mathrm{radian} / \mathrm{sec} 2$ )

The angular velocity can be calculated from the equation (4) as follows:

$$
\mathrm{W}=\int\left[\mathrm{T} / \mathrm{I} \Omega * \mathrm{dt}=\int \alpha * \mathrm{dt}\right.
$$

It can convert angular velocity to the speed from the following relationship:

$$
\mathrm{N}=(\mathrm{W} * 60) /(2 * \pi)
$$

Where $\mathrm{N}=$ rotational speed of the engine $(\mathrm{r} / \mathrm{min})$

It has been found that the rotational speed of between 80 --- 75 cycles / minute is sufficient to start the diesel engine [3].

And in our research this has to study the rate of speed that is run recycling engines manually and automatic rotation using a speed-measuring device. Figure (5) shows the device that was used to measure the speed of diesel engines.

After studying the relationship speed with time found that the average speed of recycling manually ranging between ( $85-95$ )(r.p.m) and are subject to increase and decrease $(10 \%)$ and by scalability person using a sufficient minimum to run such engines if the speed is constant and nonirreversible. Where it is known to us that recycling manually for these engines starts upward gradual speed with time from rest a very short time of (1-3) seconds so note the arrival of 
speed recycling manually to the highest value and then begin to decline gradually with time and repeated two or three starts downward gradually, as in figure ( 6 ), which shows the relationship of speed with time manually rotatable three consecutive attempts .

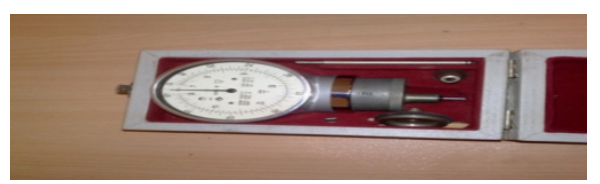

Figure 5. Engine speed measuring device

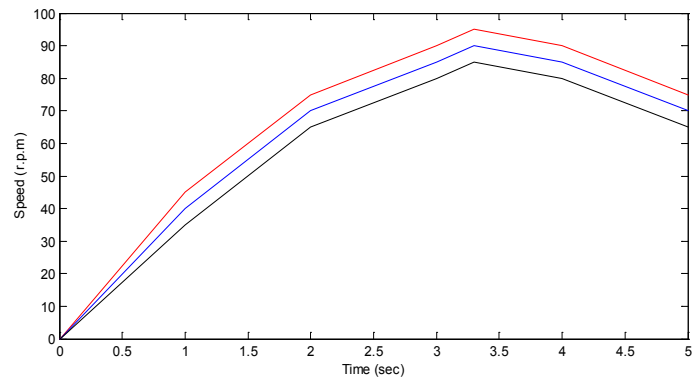

Figure 6. Relationship of speed with time manually rotation three consecutive attempts .

The speed of automatic rotation higher than the speed of rotation manually nearly double, where its range between ( 170 - 180 ) r.p.m with the acceptance of the increase or decrease by ( $2 \%$ ) according to the type of engine and as observed from the graph of speed against time in figure( 7 ). We note that the automatic rotation speed begin fixed increase with time which is very useful to start the engine and run it.There is very close agreement between the automatic rotation speed with the theoretical speed shown in figure(8).

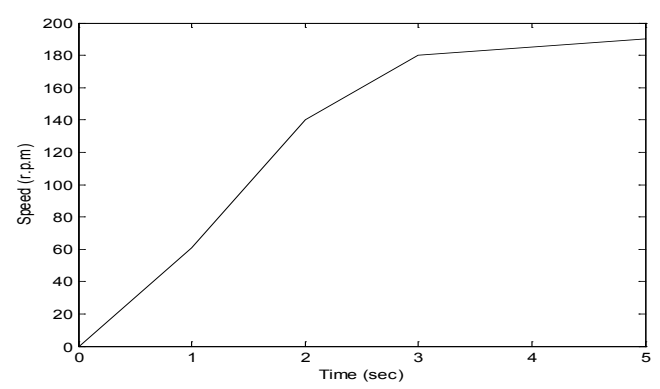

Figure 7. Automatic rotation of speed with time.

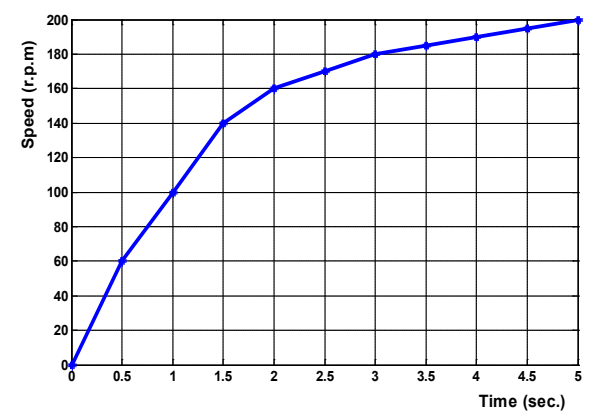

Figure 8. Theoretical speed of rotationcalculated by equation(5).

\section{Circuit Diagram of a Generator Started by Diesel Engine}

In this research has been the design and implementation of a control circuit to start electrical generator managed mediated by a diesel engine. The circuit shown in figure(9), consists of the following parts :

1. electric motor with a small gear works as DC motor, fed from a source of constant voltage (12 V DC) from the battery to generate the torque required to run the diesel engine.

2. DC motor drive( $12 \mathrm{~V} \mathrm{DC}$ ) for turn-off and works in both directions with the specified key .

3. Magnetic contactors (12V DC) used to run and turnoff the diesel engine by engine starter and engine turn-off .

4. Magnetic contactor is used to connect the load from two sources ( electricity generated Nationally or electricity from diesel generator ) .

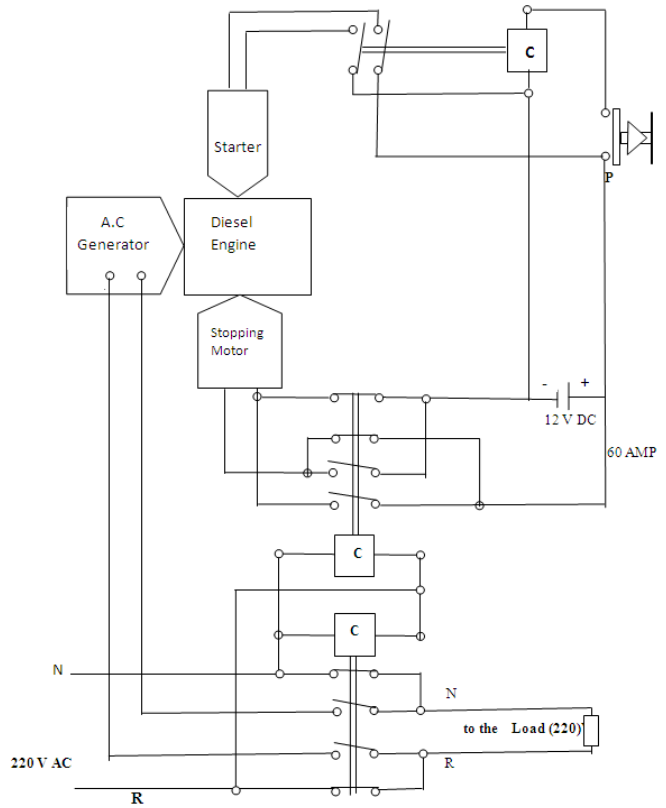

Figure 9. Electrical circuit to turn-on and turn -off the generator and fed the load from two sources

\section{Automatic Extinguishing of Diesel Engine}

In this research a designed circuit to turn-off the diesel engine automatically in the event of the return of the voltage of the national electricity and restarted in case of power from the national electricity again, using a number of electrical switches and an electric motor with a keyboard set (limit switch) and DC motor with a contactor, as shown in figure (10) .

\section{Conclusions}


In this research an electrical starter is designed and implemented for automatic starting and automatic extinguishing for diesel engines that are manually operated, which are frequently used for the purpose of power generation, household electrical and watering farms. The starter is implemented using auto- parts available in local markets, with a number of pieces of iron multi-dimensional and shapes to suit the system operating and turn-off automatically for all kinds of engines with manual rotation. It was in this research study rotatable connection speed manually and automatic with time and its impact on the speed of operation of this type of engines. As well as the circuitry is designed to be used to extinguish these engines automatically if the return voltage (the national electricity) . In addition to the above, the operation of these engines requires high effort so easy starting motor $\mathrm{ON}$ and $\mathrm{OFF}$ a lot of people use it and take advantage of them and get rid of the risk of exposure to ill use the manual lever recycling .

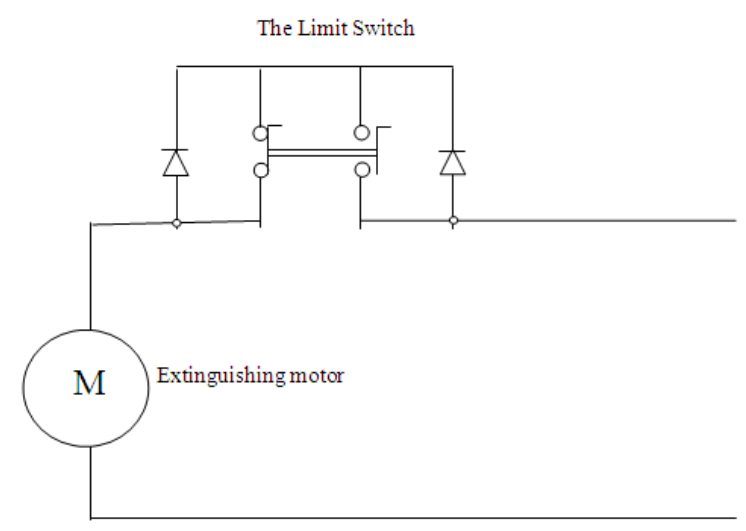

Figure 10. Electrical circuit for the extinguishing engine

\section{REFERENCES}

[1] Miller ,J. R. :"Diesel engine starting using battery-capacitor combination" Conference on Electronics For Trucks And Buses,Chicago ,Nov. 12-14,PP2071-2714,2001.

[2] Klementov,A. D.:" Theoretical and practical aspects of internal combustion engines",15th Int. Seminar On Hybrid Energy Storage Devices, Deerfield Beach,Dec. 5-7,2005.

[3] Fredric, N. et al: "History of Vehicles development" 2ndistions, Arabic translation, 1985.

[4] John ,A. B.:", An investigation into the cold Start performance of automotive diesel engines",Thesis Submitted to The University of Nottingham for the Degree of Doctor,April,1998.

[5] Heinz Heisler: " Vehicle and engine technology",Book,Volume(1),Edward Arnold Publishers, 1985.

[6] Hassan, R. : "Fundamentals of heating Motors " , Arabic book, Egypt, 1986 .

[7] Jack ,D. M.:" Elements of gas turbine propulsion", Book, McGraw-Hill Company, ,New Delhi,1996.

[8] www.faisllbughdadi.com

[9] www.islamselect.com

[10] Jane Hanna \& Stevenson, R.S:"Mechanic of machinery", Book translated to Arabic, University of Mosul,Iraq,1988.

[11] www.plamoon.net

[12] Hillier ,V. A. W.:" Fundamentals of motor vehicles technology", Book, Third Edition,London,1981. 